\title{
Sosialiasi Penerapan Sistem Pencatatan dan Pelaporan Keuangan BUMDES Berbasis Web
}

\author{
Erlina \\ erlinaroesli1966@yahoo.com \\ Universitas Sumatera Utara
}

\author{
Sirojuzilam \\ siro_juzilam@yahoo.co.id \\ Universitas Sumatera Utara
}

\begin{abstract}
ABSTRAK
Tata kelola BUMDes yang baik harus dimulai dari perencanaan yang baik hingga proses pelaksanaan dari kegiatan BUMDes setiap harinya. BUMDes Karya Tanjung masih memerlukan perbaikan tata kelola, meningkatkan daya saing dari jenis-jenis kegiatan yang ditawarkan dan sistem pengelolaan keuangan yang sudah berbasis web akuntansi BUMDES. Tujuan kegiatan profesor mengabdi ini adalah memberikan bantuan teknologi tepat guna kepada pengurus BUMDes Tanjung Pasir dalam menyusun sistem pembayaran melalui sistem akuntansi berbasis web dalam pelaporan keuangan sesuai dengan peraturan perundang-undangan yang berlaku. Metode dalam kegiatan ini adalah melalui sosialisasi sistem akuntansi BUMDES berbasis web, pelatihan Akuntansi BUMDES berbasis web dalam pencatatan dan pelaporan keuangan BUMDES, penguatan tata kelola BUMDES serta monitoring dan evaluasi. Hasil dari program kemitraan kepada masyarakat ini terciptanya kemampuan mitra penerima bantuan (BUMDes Tanjung Pasir) dalam meningkatkan kemampuan dalam mengelola BUMDES dengan memilih dan mengembangkan jenis-jenis usaha yang ada berdasarkan potensi sumberdaya lokal. Selain itu, mitra mampu melakukan pencatatan dan pelaporan keuangan yang efektif dan mudah dipahami melalui pembelajaran sistem akuntansi BUMDES berbasis web.
\end{abstract}

Kata Kunci: Sistem Akuntansi BUMDES berbasis Web; Pelaporan Keuangan. Teknologi Tepat Guna

\section{PENDAHULUAN}

Terbitnya UU Nomor 6 Tahun 2014 tentang Desa membawa kemajuan bagi desadesa di seluruh Indonesia. Desa tidak lagi sebagai wilayah yang terbelakang, namum desa mampu menjadi pusat perkembangan wilayah melalui penyaluran dana desa. Setiap desa akan mendapat alokasi dana yang bersumber dari APBN dengan jumlah yang dapat mencapai Rp1 miliar per desa. Alokasi dana desa ini merupakan stimulus bagi desa untuk mempercepat desa berbenah diri dalam meningkatkan pendapatan asli desa (PADes) sebagai optimalisasi potensi hasil usaha, hasil aset, swadaya dan partisipasi, gotong royong, dan lain-lain pendapatan asli desa serta hibah dan sumbangan yang tidak mengikat dari pihak ketiga dan pendapatan lain yang sah (Indonesia, 2014).
Tuntutan untuk memaksimalkan potensi sumberdaya tersebut berbanding lurus dengan kemampuan untuk mengelola dana tersebut untuk mengembangkan satuan unit usaha yang berada pada satu payung BUMDes (Badan Usaha Milik Desa) (Samadi, Rahman, \& Afrizal, 2013). Selain pengurus BUMDes memiliki kapasitas menemukenali dan mengembangkan potensi sumberdaya lokal sebagai sumber pendapatan BUMDes dan tata kelola yang baik dari rencana sumberdaya yang dibutuhkan, pengurus BUMDes harus mempelajari sistem pembayaran, sistem akuntansi, pencatatan dan pelaporan sesuai dengan peraturan perundang-undangan yang berlaku sebagai bentuk transparansi, akuntabilitas dan kredibilitas (Carlitz, 2013). 
Kondisi eksisting ditemukan pada BUMDes Karya Tanjung masih mengelola pencatatan dan pelaporan dalam sistem akuntansi yang sederhana. Unit-unit usaha yang dikembangkan beberapa jenis usaha perdagangan dan jasa, mencakup: biro jasa pembayaran (fast pay), pertanian, perikanan, peternakan, pengolahan makanan berbasis home industry, belum memiliki pencatatan dan pelaporan keuangan yang tidak jelas. Pengurus tidak mengetahui perihal tata kelola keuangan yang benar dan mudah diaplikasikan, identifikasi potensi sumberdaya lokal yang berkaitan dengan pemilihan dan pengembangan jenis usaha serta penerapan sistem akuntansi BUMDes berbasis aplikasi yang berkaitan dengan pencatatan dan pelaporan keuangan (Purba, Aulia, Dwilita, \& Nadra, 2018), (Umar, Usman, \& Purba, 2018).

Melalui kegiatan pengabdian kepada masyarakat dalam program Profesor Mengabdi, tim pelaksana menjalin kerjasama dengan pengurus BUMDes Karya Tanjung untuk belajar memahami tata kelola yang baik melalui sistem pencatatan dan pelaporan keuangan yang sistemik, efektif, mudah diakses, transparan dan akuntabel (Purba R. B., 2017). Dimulai dari pemetaan kondisi potensi sumberdaya desa, tata kelola dan pemilihan dan pengembangan jenis usaha sampai pada penerapan sistem akuntansi BUMDes yang baik (Zulkarnaen, 2017), (Budiono, 2015). Tujuan diselenggarakan pelatihan peningkatan kapasitas pengurus BUMDes mampu meningkatkan dan mengembangkan kualitas pengurus BUMDes untuk dapat mengembangkannya ke depan. Untuk itu perlu adanya pembelajaran dan proses penerapan yang tepat, baik dari segi waktu maupun dari sumberdaya. Hasil akhir dari pengabdian masyarakat ini berupa BUMDes yang berkualitas tentu menjadi input yang bermanfaat baik bagi desa itu sendiri maupun bagi daerah lainnya.

\section{METODE KEGIATAN}

Kegiatan yang akan dilakukan untuk memecahkan permasalahan tersebut di atas, maka metode yang diajukan untuk mengatasi dan memecahkan permasalahan tersebut adalah:

1. Sosialisasi Sistem Akuntansi BUMDes Berbasis Web

Sosialisasi pengelolaan keuangan dengan Sistem Akuntansi BUMDes berbasis web. Sosialisasi dilakukan dengan melakukan presentasi terhadap warga secara interaktif dan partisipatif terkait peningkatan kapasitas (capacity building) dalam peningkatan kualitas BUMDES (Purba R. B., 2017), (Archive, 1997).

2. Pelatihan Pengelolaan Keuangan Desa Melalui Pelatihan Akuntansi Desa Berbasis Web

Pelatihan diberikan kepada pengurus BUMDES yang ada di Desa Tanjung Pasir. Pelatihan dilakukan dengan melakukan presentasi terhadap aparatur desa secara interaktif dan partisipatif terkait peningkatan kapasitas (capacity building) yang yang didampingi oleh Tim pelaksana yang bertugas sebagai narasumber. Dalam pelatihan ini, Tim Pelaksana juga memberikan bantuan teknologi tepat guna kepada pengurus BUMDES yang telah terbentuk, berupa: Sistem Akuntansi BUMDES berbasis aplikasi dalam pencatatan dan pelaporan keuangan

3. Penguatan Tata Kelola BUMDES

Kegiatan ini dilakukan dengan memberikan bantuan modul kepada aparatur desa untuk memudahkan peserta dalam memahami tata kelola dan pengelolaan keuangan BUMDES yang efektif, efisien, transparan dan akuntabel. Pendekatan ini mengenal dua langkah utama, yaitu: penyadaran (conscientization) di tingkat individu dan pengorganisasian (community organization) di tingkat struktur dan sistem (Purba, Aulia, Dwilita, \& Nadra, 2018), (Suparjan \& Suyatno, 2003).

4. Monitoring dan evaluasi.

Melakukan monitoring dan evaluasi terhadap aparatur BUMDES di Desa Tanjung Pasir Kecamatan Pangkalan Susu dalam melaksanakan pengolaaan 
keuangan BUMDES. Monitoring dan evaluasi ini dilakukan sebulan setelah pelatihan tersebut.

\section{HASIL DAN PEMBAHASAN}

Pelaksanaan kegiatan pengabdian kepada masyarakat melalui program Profesor Mengabdi dilakukan kepada BUMDes Karya Tanjung di Desa Tanjung Pasir Kecamatan Pangkalan Susu Kabupaten Langkat telah diawali dengan berdiskusi dengan calon mitra tentang permasalahan yang dihadapi, khususnya dalam pengelolaan dan pengembangan BUMDes. Berdasarkan informasi yang terhimpun, permasalahan yang dihadapi calon mitra adalah masih rendahnya pengetahuan dan keterampilan BUMDes tentang tata kelola, khususnya dalam pencatatan dan pelaporan keuangan dalam sistem akuntansi BUMDes (Umar, Usman, \& Purba, 2018). Calon mitra masih menggunakan tata cara pencatatan dan pelaporan keuangan dengan metode yang konvensional, sehingga acapkali menemukan kendala dalam pengerjaan yang membutuhkan waktu yang cukup lama dan belum sesuai dengan standar laporan keuangan yang benar. Kondisi ini mendorong tim pelaksana untuk melakukan kegiatan pengabdian kepada masyarakat dengan tahapan sebagai berikut:

1. Sosialisasi Sistem Akuntansi BUMDES Berbasis Web

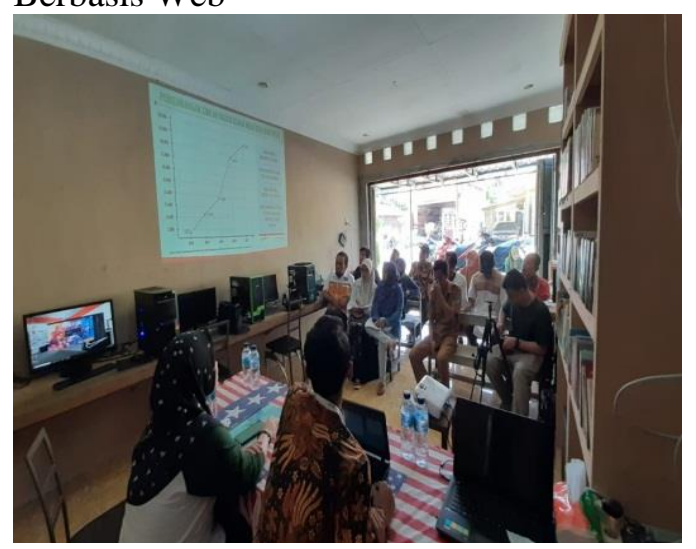

Gambar 3.1. Pelaksanaan kegiatan sosialisasi penerapan sistemakuntansi BUMDes Berbasis Web

Kegiatan ini dilakukan 1 bulan sebelum kegiatan pelatihan sistem akuntansi
BUMDes berbasis web dilaksanakan. Dalam sosialisasi ini tim pelaksana datang berkunjung ke kantor BUMDes Karya Tanjung Desa Tanjung Pasir Kecamatan Pangkalan Susu Kabupaten Langkat dan bertemu dengan Direktur BUMDes (Rudolf Panggabean) untuk membicarakan tentang kegiatan pelatihan yang akan dilaksanakan. Sosialisasi dilaksanakan secara informal dengan metode diskusi kelompok dengan pengurus BUMDes. Terjalin diskusi dua arah yang efektif dalam bina suasana yang kondusif.

Kegiatan sosialisasi ini bertujuan untuk menyatukan persepsi antara tim pelaksana dan pengurus BUMDes tentang pelaksanaan pelatihan tersebut. Selain itu, kesepatan perihal waktu, tempat dan materi pelatihan yang akan disampaikan dapat dipersiapkan sebagaimana mestinya. Tim pelaksana dan pihak BUMDes menyepakati pelaksan kegiatan sistem pelatihan akuntansi BUMDes dilaksanakan di kantor (sekretariat) BUMDes yang dijadwalkan akan dilaksanakan pada bulan depan (Juli 2019). Pihak BUMDes meminta kepada tim pelaksana agar kegiatan pelatihan ini melibatkan unsur perangkat desa, pendamping desa dan unsur kecamatan agar kesemua stakeholder mendukung kegiatan pelatihan ini untuk pengembangan BUMDes ke depannya.

2. Pelatihan Pengelolaan Keuangan Desa Melalui Pelatihan Akuntansi Desa Berbasis Web Pelatihan diberikan kepada pengurus BUMDES yang ada di Desa Tanjung Pasir. Pelatihan ini terlebih dahulu dibuka oleh Ketua Tim Pelaksana, sekaligus memberikan pemaparan tentang urgensitas pelatihan ini dilaksanakan. Dalam kesempatan itu juga Ketua Tim Pelaksana menegaskan pengelolaan keuangan dengan menggunakan Sistem Akuntansi BUMDes Berbasis Aplikasi ini mampu mendorong BUMDes menjadi unit usaha yang lebih professional dan akuntabel, sehingga mampu bersaing dengan BUMDes lainnya yang tersebar di wilayah Indonesia pada umumnya dan di Provinsi Sumatera Utara 
pada khususnya. Selanjutnya Ketua Tim pelaksana menghimbau agar kesempatan yang dimiliki oleh BUMDes Karya Tanjung tidak hanya dilakukan pada saat pelatihan ini saja, namun sistem aplikasi ini juga digunakan untuk melakukan pencatatan dan pelaporan keuangan dari unit-unit usaha yang berada di bawah naungan BUMDes Karya Tanjung.

Pada sesi berikutnya, penginputan software Sistem Akuntansi BUMDes Berbasis Web dilakukan ke dalam semua komputer dan laptop yang diakses secara on-line. Pengurus BUMDes dibimbing oleh narasumber (Angga) yang didatangkan dari Yogyakarta tentang tata cara penginputan sistem tersebut, sekaligus mekanisme penggunaannya sistem tersebut. Pada tahapan awal narasumber memaparkan filosofi penggunaan sistem aplikasi ini beserta contoh-contoh sukses dari beberapa BUMDes di Indonesia yang sudah menggunakan sistem ini. Selanjutnya proses melatih penggunaan sistem ini dilakukan kepada bendahara dan petugas keuangan BUMDes Karya Tanjung yang dilakukan ecara interaktif dan partisipatif terkait peningkatan kapasitas (capacity building). Sistem Akuntansi BUMDes Berbasis Web ini merupakanbantuan teknologi tepat guna yang diberikan oleh Tim pelaksana kepada pengurus BUMDES Karya Tanjung.

3. Penguatan Tata Kelola BUMDES

Kegiatan ini dilakukan oleh Ketua Tim Pelaksana dengan memberikan modul kepada pengurus BUMDes Karya Tanjung untuk memudahkan peserta dalam memahamai tata kelola dan pengelolaan keuangan BUMDES yang efektif, efisien, transparan dan akuntabel. Pendekatan ini mengenal dua langkah utama, yaitu: penyadaran (conscientization) di tingkat individu dan pengorganisasian (community organization) di tingkat struktur dan sistem (Suparjan \& Suyatno, 2003)s. Ketua Tim Pelaksana (Prof. Erlina) memaparkan bahwa tata kelola BUMDes yang baik terlebih dahulu dimulai dari prinsip-prinsip good corporate governance yaitu: transparan, partsipatif dan akuntabel, khususnya dalam pencatatan dan pelaporan keuangan lembaga. Pengurus BUMDes dan perangkat desa yang menjadi peserta pelatihan tampak antusias dalam mengikuti sesi ini. Hal ini terlihat dari proses tanya jawab yang silih berganti dari pengurus BUMDes, perangkat desa maupun pendamping desa yang turut hadir dalam kegiatan pelatihan ini.

4. Monitoring dan evaluasi

Kegiatan monitoring atau evaluasi terhadap pengurus BUMDES Karya Tanjung di Desa Tanjung Pasir Kecamatan Pangkalan Susu dilakukan untuk memantau sejauh mana pemahaman petugas keuangan BUMDes dalam menggunakana sistem ini dalam pencatatan dan pelaporam keuangan BUMDES. Monitoring dan evaluasi pasca pelatihan baru dilakukan dalam bentuk diskusi interaktif melalui group whatssapp yang dibentuk antara Tim Pelaksana, Sekolah BUMDes Indonesia, apartur Desa Tanjung Pasir dan pengurus BUMDes Karya Tanjung. Group Whatssapp ini dibentuk sebagai wadah pertukaran informasi terhadap kendala-kendala yang ditemukan dalam proses penggunaan sistem ini. Selain itu, group whatssapp dapat menjadi saluran informasi untuk memantau perkembangan BUMDes Karya Tanjung, khususnya dalam pencatatan dan pelaporan keuangan.

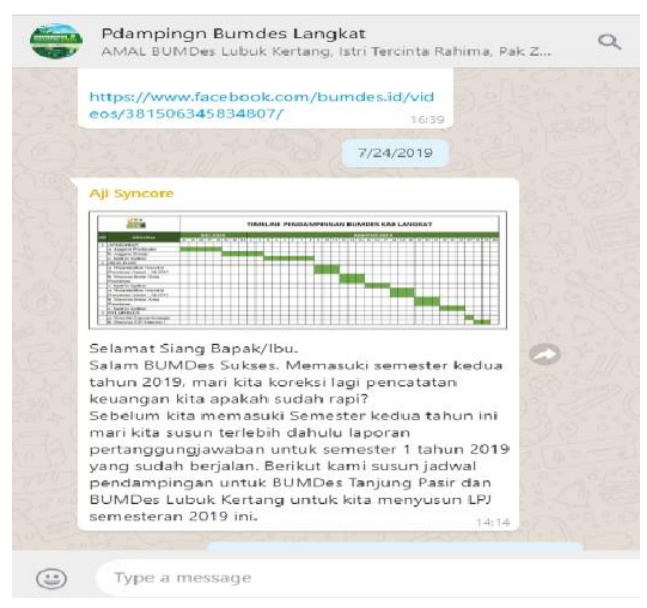

Gambar 3.2. Monitoringperkembangan pencatatan keuangan di BUMDes Karya Tanjung 


\section{KESIMPULAN DAN SARAN \\ Kesimpulan}

Kesimpulan yang dapat diambil dari kegiatan pengabdian masyarakat ini adalah:

1. Antusias pengurus BUMDes Karya Tanjung dalam pelatihan ini sangat besar. Hal ini ditunjukkan dalam bentuk kemudahan dalam pelaksanaan kegiatan pengabdian dan partisipasi kehadiran yang konsisten dalam setiap kegiatan (FGD dan pelatihan).

2. Kegiatan ini memiliki potensi yang besar untuk ditindaklanjuti bagi pengelolaan keuangan BUMDes lebih efisien, cepat, transparan dan akuntabel ke depannya. Sistem Akuntansi BUMDes Berbasis Aplikasi telah tersedia dan mudah dipahami dan diakses secara cepat.

3. Pelatihan Akuntansi BUMDes Berbasis Web ini dapat mendorong BUMDes karya Tanjung menjadi lembaga yang unggul dalam mengelola pencatatan dan pelaporan keuangan, sehingga mampu bersaing dengan BUMDes lainnya.

\section{Saran}

Saran yang diberikan dalam kegiatan ini adalah sebagai berikut :

1. Kepada Kelompok Mitra (BUMDes Karya Tanjung), untuk terus menerus memantau dan mengimplementasi Sistem Akuntansi BUMDes Berbasis Web melalui seluruh stakeholder yang terkait

2. Kepada Perguruan Tinggi, agar melakukan pembinaan dari segi illmu pengetahuan baik yang berkaitan dengan pengelolaan dan penguatan tata kelola kelembagaan.

3. Kepada Pemerintah Daerah (dalam hal ini Pemkab Langkat) agar menjadikan program sistem akuntansi BUMDes berbasis web ini sebagai salah satu program pembangunan desa. Mengingat potensi BUMDes sangat besar dalam mengembangkan pendapatan asli desa melalui pengembangan BUMDes ke depannya.

\section{Daftar Pustaka}

Archive, I. (1997). Centre For Strategic And International Studies. Analisis CSIS.

Budiono, P. (2015). Implementasi Kebijakan Badan Usaha Milik Desa (Bumdes) Di Bojonegoro (Studi di Desa Ngringinrejo Kecamatan Kalitidu Dan Desa Kedungprimpen Kecamatan Kanor). Jurnal Politik Muda, 116 -125.

Carlitz, R. (2013). Improving transparency and accountability in the budget process: An assessment of recent initiatives. Development Policy Review, s49-s67.

Indonesia, R. (2014). Undang Undang Republik Indonesia Nomor 6 Tahun 2014 Tentang Desa. Jakarta: Republik Indonesia.

Purba, R. B. (2017). Capacity Apparatus Improvement in Managing Economics and Finance towards Independent Village. IOSR Journal of Economics and Finance (IOSR-JEF), 27-31.

Purba, R., Aulia, F., Dwilita, H., \& Nadra, U. (2018). Increasing Income For Communities In Lubuk Kertang Village Through Village-Based Business Enterprises (BUMDES) Based On Mangrove Ecotourism. International Journal of Economics, Commerce and Management, 629-639.

Samadi, S., Rahman, A., \& Afrizal, A. (2013). PERANAN BADAN USAHA MILIK DESA ( BUMDES ) DALAM PENINGKATAN EKONOMI MASYARAKAT ( STUDI PADA BUMDES DESA PEKAN TEBIH KECAMATAN KEPENUHAN HULU KABUPATEN ROKAN HULU ). e-Journal Mahasiswa Prodi Manajemen, 1-19.

Suparjan, S., \& Suyatno, H. (2003). Pengembangan masyarakat : dari pembangunan sampai pemberdayaan. Yogyakarta: Aditya Media. 
Umar, H., Usman, S., \& Purba, R. B. (2018). THE INFLUENCE OF INTERNAL CONTROL AND COMPETENCE OF HUMAN RESOURCES ON VILLAGE FUND MANAGEMENT AND THE IMPLICATIONS ON THE QUALITY OF VILLAGE FINANCIAL REPORTS. International Journal of Civil Engineering and Technology, 15251531.
Zulkarnaen, R. M. (2017). Pengembangan Potensi Ekonomi Desa Melalui Badan Usaha Milik Desa (BUMDES) Pondok Salam Kabupaten Purwakarta. Dharmakarya: Jurnal Aplikasi Ipteks untuk Masyarakat, 1-4. 